\title{
Dynamic design method of wellbore structure during drilling operation based on LWD
}

\author{
Sheng Ya-nan ${ }^{1} \cdot$ Li Weiting $^{1} \cdot$ Lan Kai $^{2} \cdot$ Jiang Jinbao ${ }^{1} \cdot$ Kong Hua $^{1}$
}

Received: 16 July 2020 / Accepted: 13 November 2020 / Published online: 27 November 2020

(c) The Author(s) 2020

\begin{abstract}
At present, there is no good method or technology for quantitative evaluation of wellbore structure and engineering risk in the process of deep well drilling in complex formation, and there is no rational understanding of engineering risk mechanism. With the development of MWD and transmission technology, the formation pressure and rock mechanics parameters of the drilled section can be accurately determined in the process of drilling, which provides a basis for the well bore structure and engineering risk assessment in the process of drilling. This paper makes full use of the advantages of MWD and other technologies to seek a method to improve the accuracy of formation pressure prediction with narrow safe density window On this basis, the risk identification methods of leakage, blowout, collapse, sticking and other engineering risks in the process of drilling are studied, and the risk assessment method of dynamic wellbore structure in the process of drilling is established; at the same time, the uncertain parameters in the existing wellbore structure design method are studied, and the design method is improved, so as to minimize the risk of well structure design.
\end{abstract}

Keywords Formation pressure with credibility $\cdot$ LWD (logging while drilling) $\cdot$ Dynamic evaluation of drilling risk · Optimization design of wellbore structure

\section{Introduction}

The problem of narrow safe density window in the drilling of deep and complex formation is always one of the problems faced by the well structure design and safe construction. With the increase in well depth, the problem of narrow safe density window becomes more and more prominent (Xiwen 2006; Deli 2004; Yijin and Jian 2005). Therefore, advanced technologies such as underbalanced drilling, pressure controlled drilling and gas filled drilling are adopted at home and abroad, as well as risk assessment technologies such as pre drilling wellbore structure design and risk assessment method based on probability statistics, which solve this problem to a certain extent (Sayers et al. 2006; Zhou yingcao, Yang Xiongwen, Fang Shiliang,, et al. 2011;

Sheng Ya-nan

syn4465877@163.com

1 Drilling Engineering and Technology Research Institute, Zhongyuan Petroleum Engineering Co., Ltd., SINOPEC, Puyang 457001, China

2 Southwest Drilling Company, Zhongyuan Petroleum Engineering Co., Ltd., Chengdu 610000, China
Mingyan 2007). Among them, the risk assessment technology can quantitatively assess the engineering risk based on the existing equipment and technology, combined with the theory of risk analysis and so on. It is very necessary for the deep well complex formation drilling with high risk and high investment, and is conducive to the realization of the purpose of safe and efficient deep well complex formation drilling. Through investigation, the method of pre drilling wellbore structure design and risk assessment based on probability statistics is to use the adjacent well logging data or seismic data to make probability prediction of the safe density window of the target well, and to carry out quantitative assessment of engineering risks such as leakage, blowout and collapse card for the existing wellbore structure design scheme before drilling, so as to improve it. This method has relatively rich well efficiency for the adjacent well data. Meanwhile in separate studies (Xiaoming and Pejman 2018; Tahmasebi and Kamrava 2019), other researchers have found that several other parameters such as temperature, grain shape, fluid, and stress can control the integrity of formation and well. With the increasing depth of deep wells in complex formations and the drilling of unproved blocks, the abundance of data from adjacent wells is greatly limited,

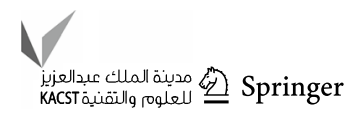


which reduces the accuracy of risk assessment techniques such as regional probability statistics. At the same time, at present, there is no good method or technology for quantitative assessment of wellbore structure and engineering risk in the process of deep well drilling in complex formation. More accident statistics methods are used to establish fault tree model, bow knot model, safety barrier model, etc., and the wellbore structure and engineering risk in the process of drilling are assessed from a macroperspective in combination with drilling conditions, lacking of understanding of risk mechanism (Liu Jianhua et al. 2013; Skogdalen 2012; Khakzad et al. 2013; Zhichuan et al. 2017; Zhilong, et al. 2009; Gundersen and Aamodt 2012). With the development of MWD (Measurement While Drilling) and transmission technology, the formation pressure and rock mechanics parameters of the drilled section can be accurately determined in the process of drilling, which provides the basis for the well structure and engineering risk assessment in the process of drilling, and can make full use of the advantages of this technology, combined with the risk assessment of the pre drilling well structure based on probability statistics. The theory and thinking of this method are to seek for a new method to optimize the well bore structure in the process of deep well drilling in complex formation by using LWD (Logging While Drilling). In order to solve this problem, this paper proposes a new method of dynamic well bore structure optimization design based on LWD data, which makes full use of the advantages of LWD and other technologies to seek a method to improve the accuracy of formation pressure prediction with narrow safe density window, and eliminates the potential risks caused by the uncertain parameters of the ground layer from the root, and on this basis, the leakage and blowout in the drilling process are analyzed. The risk identification methods of engineering, such as collapse, card, etc., are studied to establish the risk assessment method of dynamic wellbore structure in the process of drilling; at the same time, the uncertain parameters in the existing wellbore structure design method are studied to improve the design method, so as to minimize the risk of wellbore structure design.

\section{Prediction of formation pressure with credibility before drilling}

In order to fully consider the uncertainty of formation parameters in deep well drilling in complex formation, Professor Guan Zhichuan proposed the formation pressure prediction method based on probability statistics (Ke et al. 2009). Based on the principle of this method, the formation pressure of the target deep well and complex formation well is predicted with the seismic data. Combined with logging data while drilling, the drilled formation pressure is corrected, and then the pressure of the undrilled formation is predicted again. One of the most important advantages of using seismic interval velocity ratio to predict the target well pressure is that it is not affected by the abundance of adjacent well data. At the same time, it is beneficial to correct the pressure and relevant calculation parameters of the drilled formation by combining MWD, LWD. The Eaton, Fillippone and effective stress method are used to calculate the formation pore pressure, and the specific process is shown in Fig. 9.

By using this method, the distribution zone of formation pore pressure with credibility can be obtained, as shown in Fig. 1.

Among them, the lower limit of uncertainty is composed of the calculated value of formation pore pressure with a cumulative probability density of $5 \%$, and the upper limit of uncertainty is composed of the calculated value of formation pore pressure with a cumulative probability density of $95 \%$. Take the calculation of formation pore pressure at $2800 \mathrm{~m}$ as an example, and its principle is shown in Fig. 2.

Huang Rongzun method is used to calculate formation fracture pressure (Qining 1983), the calculation formula is as follows:

$P_{\mathrm{f}}=\frac{3 \sigma_{\mathrm{h}}-\sigma_{\mathrm{H}}-\left(\alpha \frac{2-3 \mu}{1-\mu}-f\right) P_{\mathrm{p}}+S_{\mathrm{t}}}{1-\alpha \frac{1-2 \mu}{1-\mu}+f}$

In formula, $P_{f}$-Fracture pressure, $\mathrm{g} / \mathrm{cm}^{3} ; P_{p}$-Pore pressure, $\mathrm{g} / \mathrm{cm}^{3} ; S_{t}$-Uniaxial tensile strength, MPa; $\sigma_{H}-$ Maximum horizontal in-situ stress, $\mathrm{g} / \mathrm{cm}^{3} ; \sigma_{h}$-Minimum horizontal in-situ stress, $\mathrm{g} / \mathrm{cm}^{3} ; u$-Poisson's ratio, dimensionless; $\alpha$-Biot coefficient, dimensionless; $f$-Porosity, $\%$.

The calculation of formation fracture pressure needs to use the formation pore pressure, so the calculated value of the formation fracture pressure also contains the same reliability distribution zone; at the same time, the rock mechanics parameters in the formula can be transplanted and calculated from the adjacent well logging data according to different geological layers.

\section{Real-time correction of formation pressure with credibility}

By analyzing the prediction method of formation pressure with confidence before drilling based on seismic interval velocity, it can be seen that in Fig. 3, the Eaton index distribution obtained by inversion of formula (2) is the statistical result of the whole well section, as shown in formula (3) and Fig. 4. 
Fig. 1 Prediction flowchart of formation pore pressure with credibility
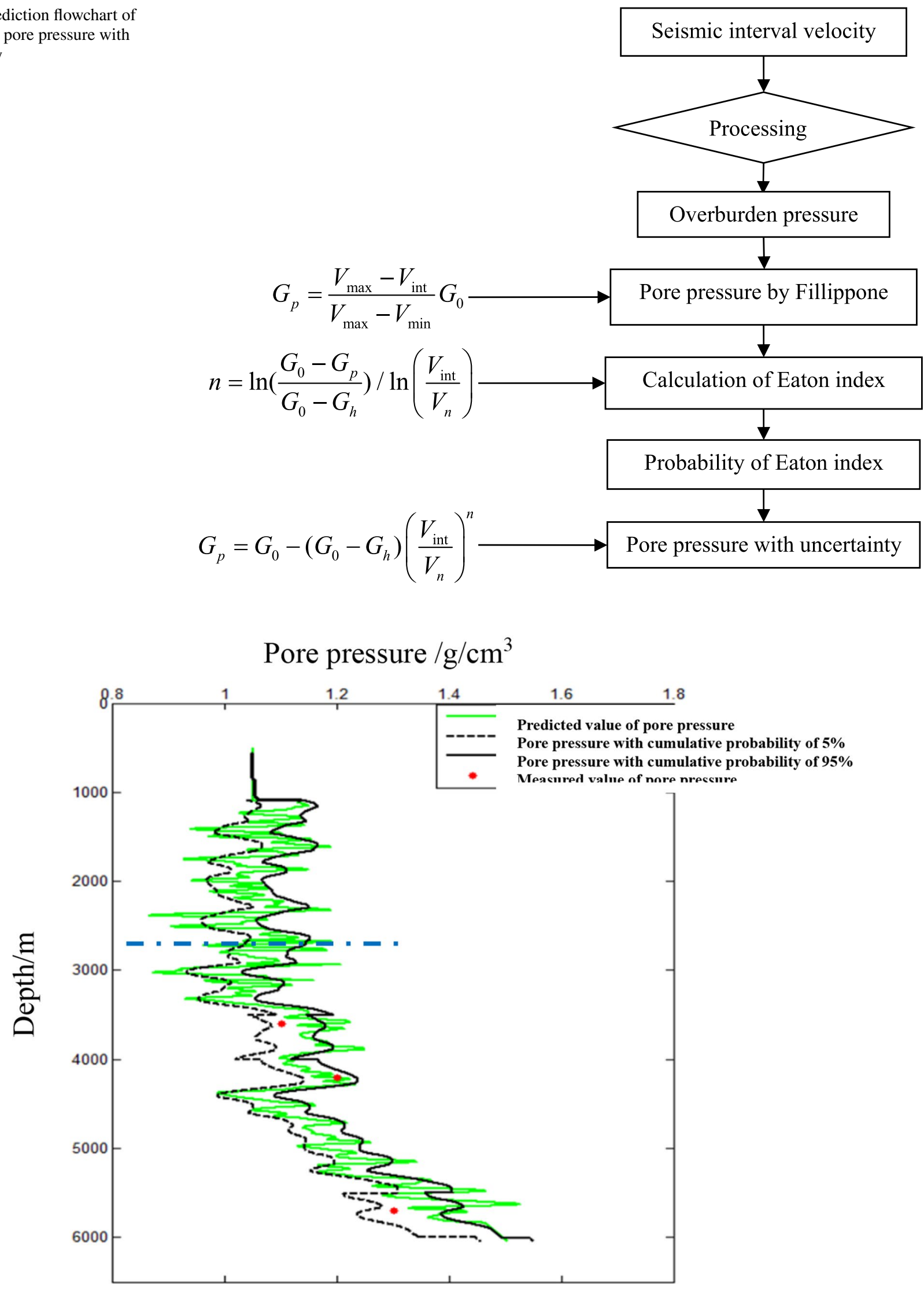

Fig. 2 Distribution zone of formation pore pressure with credibility 


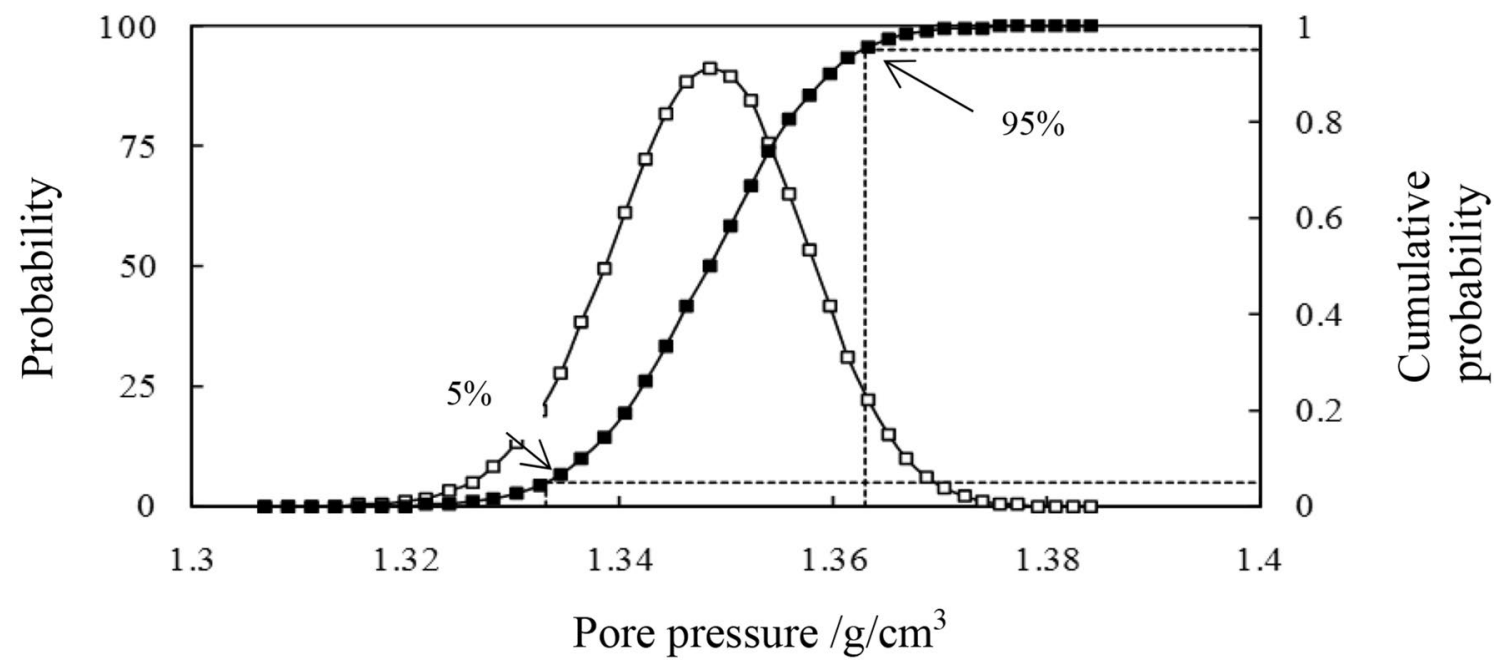

Fig. 3 Probability distribution of formation pore pressure at $2800 \mathrm{~m}$

Fig. 4 Eaton index distribution of the whole well section

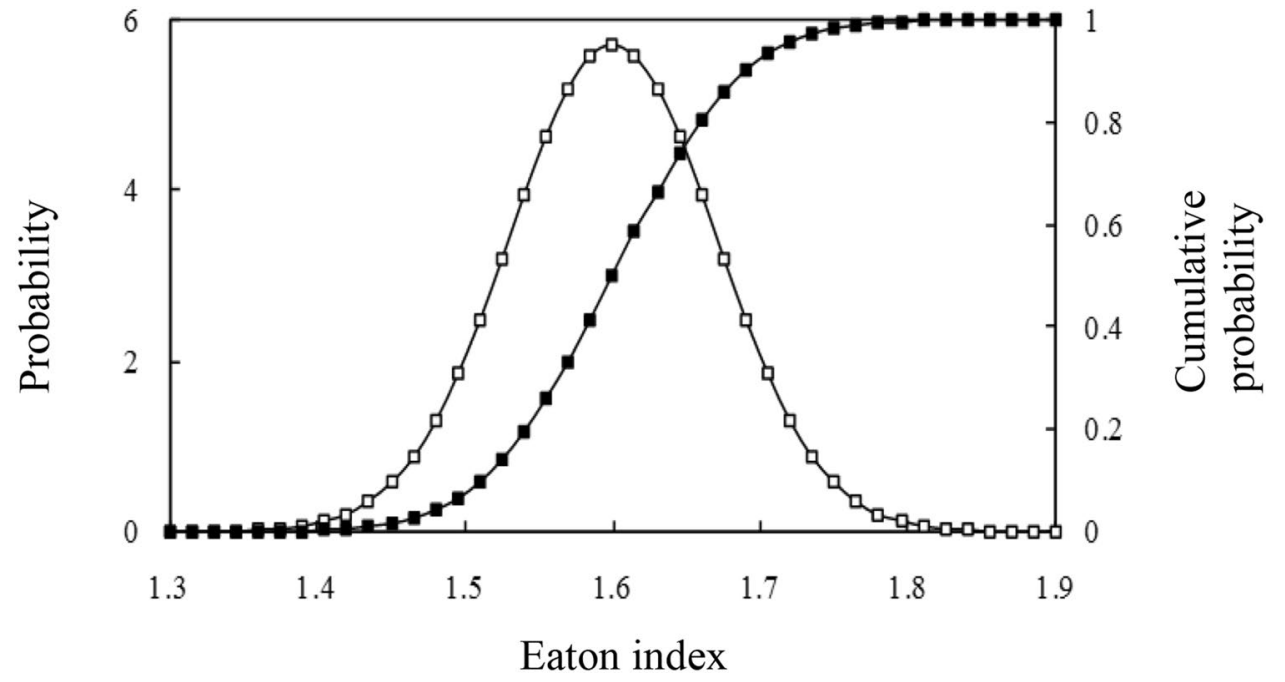

$n=\ln \left(\frac{G_{0}-G_{\mathrm{p}}}{G_{0}-G_{\mathrm{h}}}\right) / \ln \left(\frac{V_{\mathrm{int}}}{V_{\mathrm{n}}}\right)$

$\left\{\begin{array}{l}P(x)=\frac{1}{\sqrt{2 \pi \sigma}} e^{-\frac{(x-\mu)^{2}}{2 \sigma^{2}}} \\ F(x)=\frac{1}{\sqrt{2 \pi \sigma}} \int_{-\infty}^{x} e^{-\frac{(t-\mu)^{2}}{2 \sigma^{2}} d t}\end{array}\right.$

As the Eaton index changes with the well depth, the method in Sect. 1 makes probability statistics on the Eaton index of the whole well section to get the formation pressure distribution under different confidence conditions. Although the calculation results have sufficient accuracy, for the wells with large change of Eaton index along the well depth, the predicted formation pressure distribution belt with confidence is wide, which is not conducive to narrow safety casing design and risk avoidance of density window formation. Therefore, we can use LWD data to re-invert the Eaton index of the drilled formation and find a reasonable method to correct the predicted pressure distribution zone of the lower undrilled formation.

It is assumed that the Eaton index obtained by inversion of formula (2) based on seismic interval velocity before drilling is a large sample bank $n(h)$. Where, $h$ is the depth of the target well, m. The depth of the drilled section is $h_{1}$. The formation pore pressure obtained by LWD is $G_{p}^{\prime}$ $\mathrm{g} / \mathrm{cm}^{3}$. Then, the Eaton index of the drilled formation can be modified: 
$n^{\prime}\left(h_{1}\right)=\left(\ln \frac{G_{0}-G_{\mathrm{p}}^{\prime}}{G_{0}-G_{\mathrm{h}}}\right) / \ln \left(\frac{V_{\mathrm{in}}}{V_{\mathrm{n}}}\right)$

In formula, $G_{h}-$ Hydrostatic press.

ure, $\mathrm{g} / \mathrm{cm}^{3} ; G_{0}$-Overburden pressure gradient, $\mathrm{g} / \mathrm{cm}^{3} ; V_{\mathrm{n}}$ Interval velocity under normal compaction condition, $\mathrm{m} / \mathrm{s} ; V_{\text {in }}$ Interval velocity, $\mathrm{m} / \mathrm{s}$.

The Eaton index of drilled formation corrected by LWD is regarded as a small sample library $n^{\prime}\left(h_{1}\right)$ According to the previous hypothesis, the Eaton index of the whole well section obtained by seismic interval velocity inversion before drilling is a large sample library $n(h)$. The Eaton index of 0 - $h_{1}$ well section (drilled section) is small sample library $n\left(h_{1}\right)$. Replacing $n\left(h_{1}\right)$ with $n^{\prime}\left(h_{1}\right)$ to form a new large sample library $n^{\prime}(h)$ Then, the distribution form of Eaton index in the new large sample database can be obtained:

$\left\{\begin{array}{l}P^{\prime}(x)=\frac{1}{\sqrt{2 \pi \sigma}} e^{-\frac{(x-\mu)^{2}}{2 \sigma^{2}}} \\ F^{\prime}(x)=\frac{1}{\sqrt{2 \pi \sigma}} \int_{-\infty}^{x} e^{-\frac{(t-\mu)^{2}}{2 \sigma^{2}} d t}\end{array}\right.$

Fig. 5 Prediction flowchart of formation pore pressure with credibility based on LWD
Therefore, according to the modified Eaton index distribution form, combined with the method in Sect. 1, the realtime correction can be made for the pore pressure distribution zone of the undrilled formation with credibility. The specific process is shown in Fig. 5.

For formation fracture pressure, it can be seen from formula (1) that it can be corrected in real time with the correction of formation pore pressure. At the same time, many rock mechanics parameters are involved in the calculation model, which are related to geological stratification. In the previous calculation, the adjacent well logging data is generally used for regional transplant prediction, and the same geological stratification is regarded as fixed value for calculation, so there is uncertainty in its value. In order to obtain more accurate prediction value of formation fracture pressure, the LWD data can be used for correction. The specific steps are as follows:

a. According to the real-time correction value of formation pore pressure, the fracture pressure is corrected:

$$
P_{f}^{\prime}=\frac{3 \sigma_{\mathrm{h}}-\sigma_{\mathrm{h}}-\left(\alpha \frac{2-3 \mu}{1-\mu}-f\right) P_{\mathrm{p}}^{\prime}+S_{\mathrm{t}}}{1-\alpha \frac{1-2 \mu}{1-\mu}+f}
$$

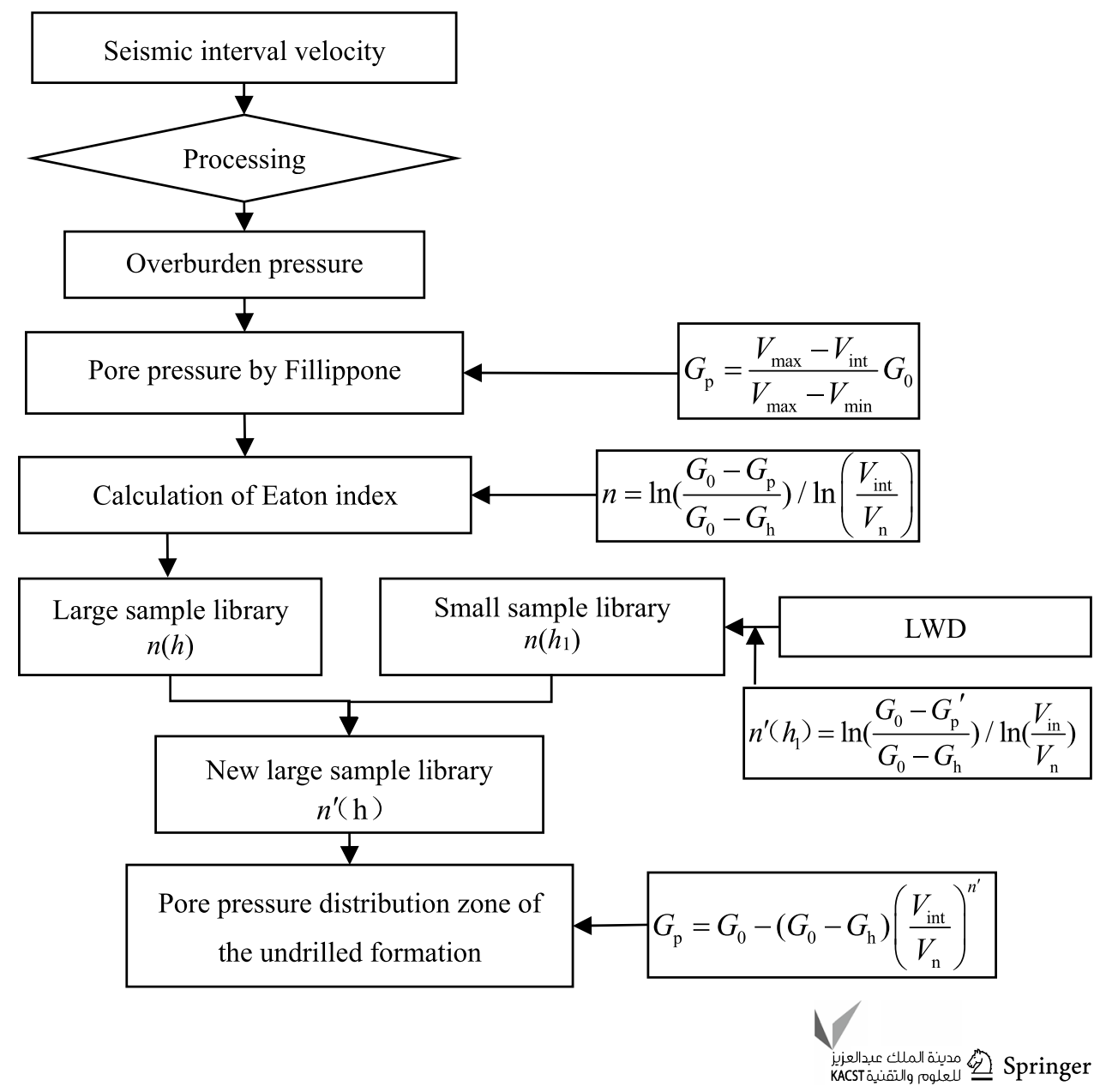


$\boldsymbol{b}$. The rock mechanical parameters of the next geological layer are predicted by using the data of adjacent wells before drilling are $x\left(\sigma_{h}, \sigma_{H}, \sigma, \mu, f, S_{t}\right)$. When drilling to the place $\Delta h$ from the top of the next geological layer, it is considered that the average value $\overline{x^{\prime}}\left(\overline{\sigma_{h}^{\prime}}, \overline{\sigma_{H}^{\prime}}, \overline{\alpha^{\prime}}, \overline{\mu^{\prime}}, \overline{f^{\prime}}, \overline{S_{t}^{\prime}}\right)$ of the rock mechanical parameters $x^{\prime}\left(\sigma_{h}^{\prime}, \sigma_{H}^{\prime}, \sigma^{\prime}, \mu^{\prime}, f^{\prime}, S_{t}^{\prime}\right)$ obtained by LWD in this geological layer is the true value of the layer. The formation fracture pressure of the local geological layer is recalculated:

$P_{f}^{\prime}=\frac{3 \overline{\sigma_{\mathrm{h}}^{\prime}}-\overline{\sigma_{\mathrm{H}}^{\prime}}-\left(\overline{\sigma^{\prime}} \frac{2-3 \overline{\mu^{\prime}}}{1-\mu^{\prime}}-\overline{f^{\prime}}\right) P_{\mathrm{p}}^{\prime}+S_{\mathrm{t}}^{\prime}}{\overline{\sigma^{\prime}} \frac{1-2 \overline{\mu^{\prime}}}{1-\mu^{\prime}}+\overline{f^{\prime}}}$

$c$. If continue drilling $\delta h$, the average value $\overline{x^{\prime \prime}}$ of the rock mechanical parameters in the interval $\Delta h+\delta h$ of the geological layer can be obtained by LWD. When $\overline{\mid x^{\prime \prime}-x^{\prime}} \mid \overline{x^{\prime}}\left(\overline{\sigma_{h}^{\prime}}, \overline{\sigma_{H}^{\prime}}\right.$ $\left.\overline{\alpha^{\prime}}, \overline{\mu^{\prime}}, \overline{f^{\prime}}, \overline{S_{t}^{\prime}}\right)$ are replaced by $\overline{x^{\prime \prime}}$ The formation fracture pressure of the local geological layer is recalculated.

$\boldsymbol{d}$. Repeat step c until this geological layer is completed.

Therefore, the method of formation pressure prediction with credibility based on LWD data is established. By using this method, the pore pressure and formation fracture pressure of the lower undrilled formation with credibility can be corrected based on the data while drilling, which not only has the advantage of the method of formation pressure prediction with credibility before drilling in Sect. 1, but also can make up for the lack of data abundance of adjacent wells. The prediction error improves the pressure prediction accuracy of the undrilled formation.

Taking a foreign offshore drilling as an example, the well has been drilled, and its logging data and adjacent well data are relatively comprehensive. The water depth of the well is $58 \mathrm{~m}$, and the completed drilling depth is $4267 \mathrm{~m}$.

Firstly, the method established in this paper is used to predict the formation pressure profile of the whole well section with reliability (as shown in Fig. 6 (a)). Assuming drilling to $1520 \mathrm{~m}$, the logging data of the drilled section can be used as logging data while drilling. The method established in this paper is used to predict the formation pressure of the undrilled formation, as shown in Fig. 6 (b).

\section{Dynamic risk assessment of wellbore structure during drilling}

According to the pressure balance constraints, the risk assessment of the existing well bore structure design scheme can be carried out in the last set up safe drilling fluid density window with credibility based on the revised LWD data. In order to ensure the safety of the open hole section, the following pressure balance constraints must be met (Yan 2001; Moos and Peska 2003):

Prevention of well kick:

\section{Equivalent drilling fluid density $/ \mathrm{g} / \mathrm{cm}^{3}$}

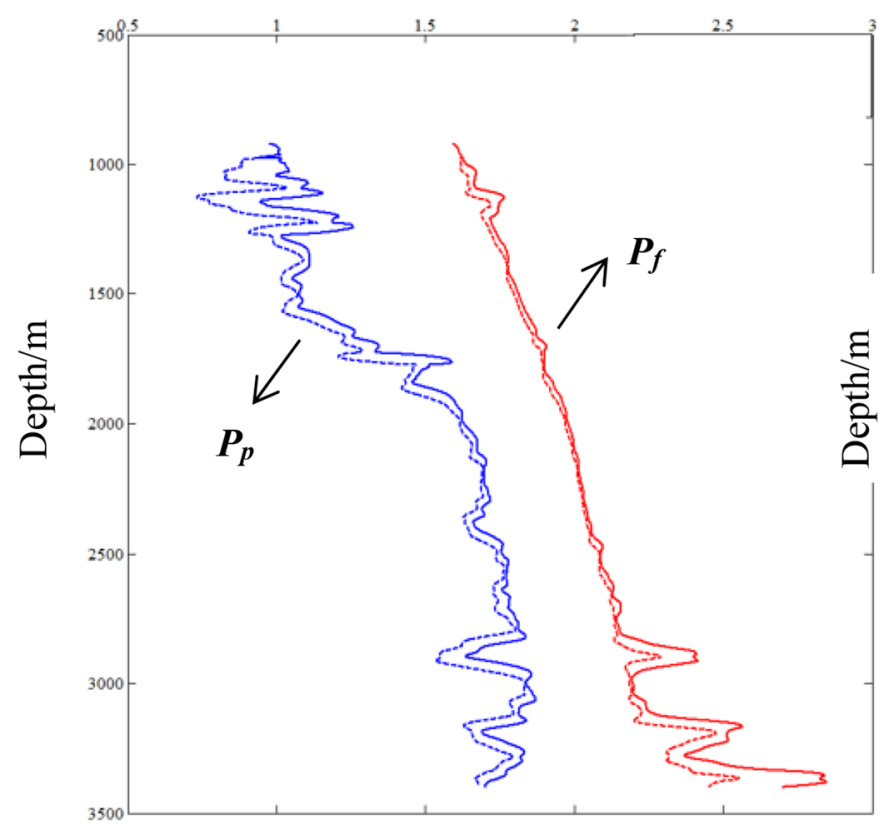

a Prediction results before drilling

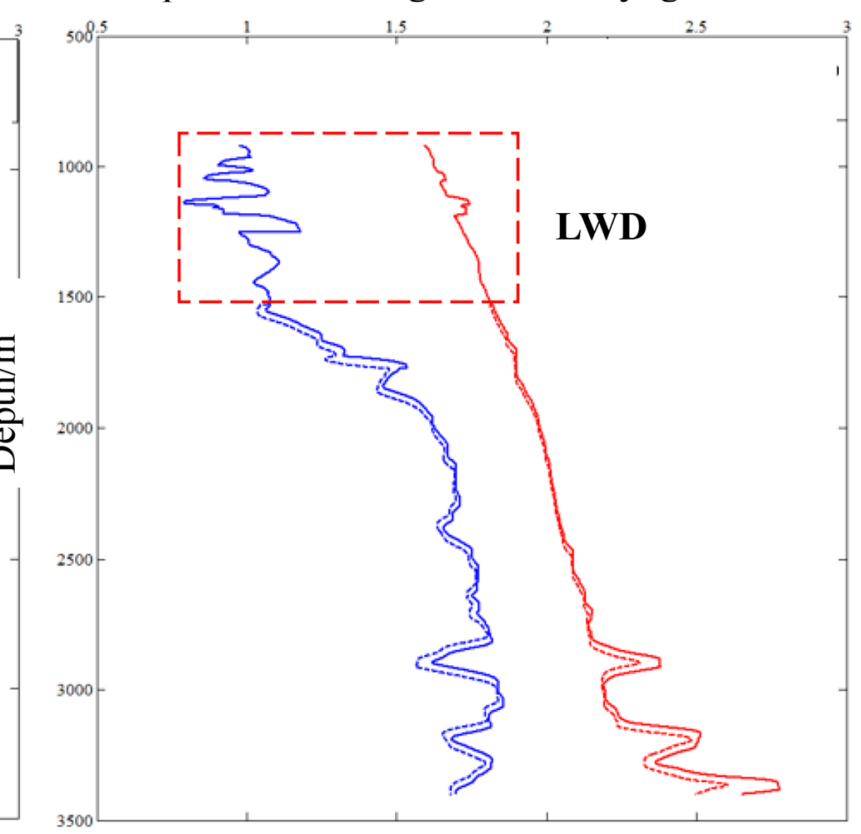

b Correction results based on LWD data

Fig. 6 Real-time correction of formation pressure with credibility based on LWD 
$\rho_{\mathrm{m}}\left(H_{i}\right) \geq \rho_{\mathrm{p} \max }+S_{\mathrm{b}}+\Delta \rho$

Prevention of differential pipe-sticking:

$\left(\rho_{\mathrm{m}}\left(H_{i}\right)-\rho_{\mathrm{p} \min }\right) \times H_{\mathrm{p} \min } \times 0.00981 \leq \Delta P$

Prevention of lost circulation in the drilling process:

$\rho_{\mathrm{m}}\left(H_{i}\right)+S_{\mathrm{g}}+S_{\mathrm{f}} \leq \rho_{\mathrm{f} \text { min }}$

Prevention of lost circulation when shut in:

$\rho_{\mathrm{m}}\left(H_{i}\right)+S_{\mathrm{k}} \times \frac{H_{i}}{H_{\mathrm{n}-1}}+S_{\mathrm{f}} \leq \rho_{\mathrm{f}}\left(H_{\mathrm{n}-1}\right)$

In formula, $S_{b}-$ Swab pressure coefficient, $\mathrm{g} / \mathrm{cm}^{3} ; S_{k}-$ Well kick tolerance, $\mathrm{g} / \mathrm{cm}^{3} ; S_{g}$ - Surge pressure coefficient, $\mathrm{g} / \mathrm{cm}^{3} ; \rho_{\mathrm{m}}\left(H_{i}\right)$-Static equivalent density of drilling fluid, $\mathrm{g} / \mathrm{cm}^{3} ; \rho_{\mathrm{pmax}}, \rho_{\mathrm{p} \text { min }}$-Maximum and minimum value of the lower limit curve of the density window of safe drilling fluid, $\mathrm{g} / \mathrm{cm}^{3} ; \Delta P$-Allowable value of differential pipe-sticking, $\mathrm{MPa} ; S_{f}$-Safety factor of fracture pressure, $\mathrm{g} / \mathrm{cm}^{3} ; \Delta \rho-$ Additional drilling fluid density, $\mathrm{g} / \mathrm{cm}^{3} ; \rho_{\mathrm{f} \text { min }}$-Minimum value of upper limit curve of density window of safe drilling fluid, $\mathrm{g} / \mathrm{cm}^{3} ; H_{\mathrm{p} \min }$-Well depth of minimum formation pore pressure, $\mathrm{m} ; H_{\mathrm{n}-1}$-Depth of casing shoe of previous casing, $\mathrm{m}$.

In the safe drilling fluid density window with credibility $J$, it is considered that the prediction of formation pressure is accurate and reliable enough. Therefore, the well kick tolerance $S_{k}$ and safety factor of fracture pressure $S_{f}$ can be ignored. Furthermore, the formula (11) in the pressure balance constraint can be ignored, and formula (10) is changed into:

$\rho_{\mathrm{m}}\left(H_{i}\right)+S_{\mathrm{g}} \leq \rho_{\mathrm{f} \min }$

Therefore, formulas (8), (9) and (12) constitute the pressure balance constraint condition under the condition of credibility $J$.

If the design drilling fluid density of the undrilled formation in the existing well structure design scheme meets the requirements of formulas (8), (9) and (12), it is considered that the current well structure design scheme has no engineering risks such as leakage, blowout and collapse. If not, the risk can be quantitatively evaluated according to the following formula:

Risk of well kick:

$R_{k(h)}=p\left(\rho_{\mathrm{m}}(h)-S_{\mathrm{b}}-\Delta \rho<\rho_{u p}(h)\right)=1-F_{\rho_{\mathrm{p}}(h)}\left(\rho_{\mathrm{m}}(h)-S_{\mathrm{b}}-\Delta \rho\right)$
Risk of lost circulation in the drilling process:

$R_{l(h)}=p\left(\rho_{m}(h)+S_{g}>\rho_{u p}(h)\right)=F_{\rho_{f}(h)}\left(\rho_{m}\left(h_{i}\right)+S_{g}\right)$

In formula, $p_{x}$ Risk probability. $\rho_{u p} \backslash \rho_{\text {down }}$-Equivalent density corresponding to the lower limit curve and upper limit curve of safe drilling fluid density window with credibility at well depth $h, \mathrm{~g} / \mathrm{cm}^{3} . F_{\rho_{p}(h)}(x)$-Cumulative probability distribution of formation pore pressure at well depth $h . F_{\rho r(h)}(x)$ Cumulative probability distribution of formation fracture pressure at well depth $h$.

According to the above model, the dynamic risk assessment can be carried out for the existing well bore structure design scheme in the process of drilling. If the assessment result indicates that there is a high engineering risk, the existing well bore structure design scheme shall be adjusted and the risk assessment shall be carried out again until the pressure balance constraint condition under the condition of credibility $J$ is met.

As an example of offshore drilling, the well has been drilled, and the well logging data and downhole accidents such as leakage, blowout and collapse are known, which can be used as a reference to verify the accuracy and reliability of this method. When drilling to $1520 \mathrm{~m}$, the formation pressure with credibility in the undrilled formation corrected by using LWD data (drilled logging data) is shown in Fig. 6 (b). The method in this section is used to evaluate the engineering risk of the existing well bore structure design scheme (Table 1 and Fig. 7) in the undrilled formation. The statistics of actual drilling engineering accidents is shown in Fig. 7. The results of risk assessment are shown in Fig. 8. It is clearly shown that there is kick risk at $1700 \mathrm{~m}$, with the risk probability of close to $100 \%$. There is lost circulation risk at $1800 \mathrm{~m}$ and $2600 \mathrm{~m}$, with the risk probability of close to $100 \%$. Compared with the statistical results of actual drilling accidents in Fig. 7, it can be seen that several engineering risks with high risks are consistent with the accident types recorded in the actual drilling and the corresponding well depth, which shows that this method can be used to carry out an effective quantitative risk assessment of the well structure, and the assessment results have a high accuracy. At the same time, with the gradual increase in drilling depth, the accuracy of formation pressure prediction in the undrilled formation will be further improved by using the correction of LWD data, and then the accuracy and reliability of the risk assessment results of the existing wellbore structure in the undrilled formation will be further improved by using this method.

Risk of differential pipe-sticking:

$$
R_{s k(h)}=p\left(\rho_{\mathrm{m}}(h)-\frac{\Delta P}{0.00981 \cdot h}>\rho_{\text {down }}(h)\right)=F_{\rho_{\mathrm{p}}(h)}\left(\rho_{\mathrm{m}}(h)-\frac{\overline{\Delta P}}{0.00981 \cdot h}\right)
$$


Table.1 Wellbore structure

\begin{tabular}{lllll}
\hline Casing program & Borehole size /in & Depth/ft & Casing size /in & $\begin{array}{l}\text { Drilling } \\
\text { fluid den- } \\
\text { sity/ppg }\end{array}$ \\
\hline Conductor & 36 & 525 & 30 & 8.7 \\
First level & 26 & 3020 & 20 & $8.7-14$ \\
Second level & 17 & 5997 & $13-(3 / 8)$ & $9.5-15.8$ \\
Third level & $12-(1 / 4)$ & 8088 & $9-(5 / 8)$ & $13.4-15.8$ \\
Fourth level & $8-(1 / 2)$ & 11030 & 7 & $15.3-16.7$ \\
Fifth level & 6 & 14000 & 6 & $14.7-15$ \\
\hline
\end{tabular}

Fig. 7 Actual drilling engineering accidents

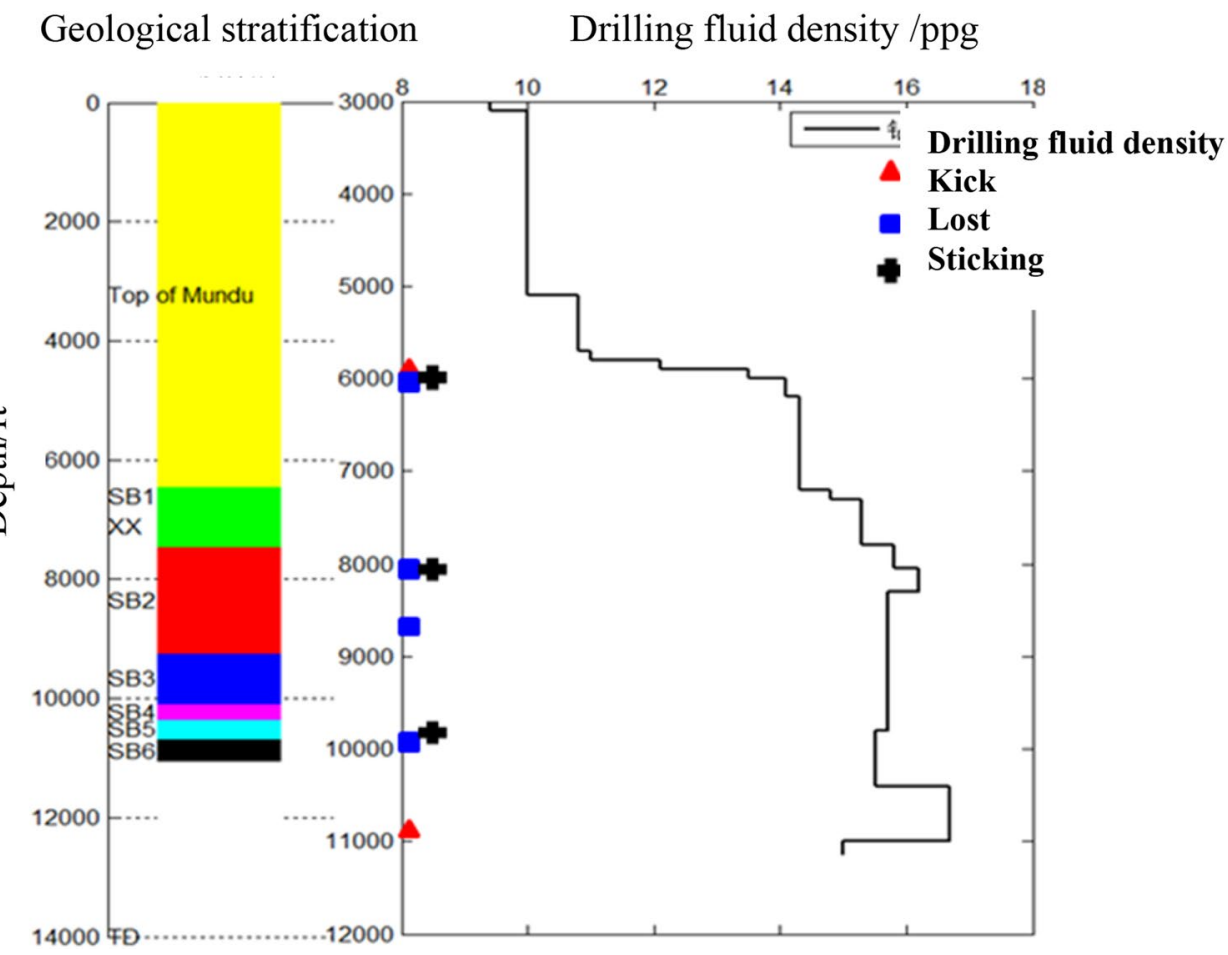

\section{Dynamic optimization design of wellbore structure during drilling}

Based on the prediction formation pressure with credibility before drilling, the wellbore structure design method with formulas (8), (9), and (12) as the constraint conditions of safe density window is established. This method improves the reliability of wellbore structure design, thus reducing the potential risk of wellbore structure design scheme. However, through the analysis of Sect. 1, although the prediction method of formation pressure with credibility before drilling can improve the reliability of formation pressure prediction, for the drilling of deep well with complex formation with low abundance of adjacent well data, it is also necessary to use logging data while drilling to modify it in real time, so as to improve the prediction accuracy of formation pressure to the greatest extent. At the same time, if steps are used in the drilling process. The third method predicts that there is a great risk in the design scheme of the existing wellbore structure of the undrilled formation, which should be adjusted to avoid the risk. Therefore, this paper proposes a dynamic wellbore 
Fig. 8 Dynamic risk assessment results

Fig. 9 Dynamic optimization design of wellbore structure

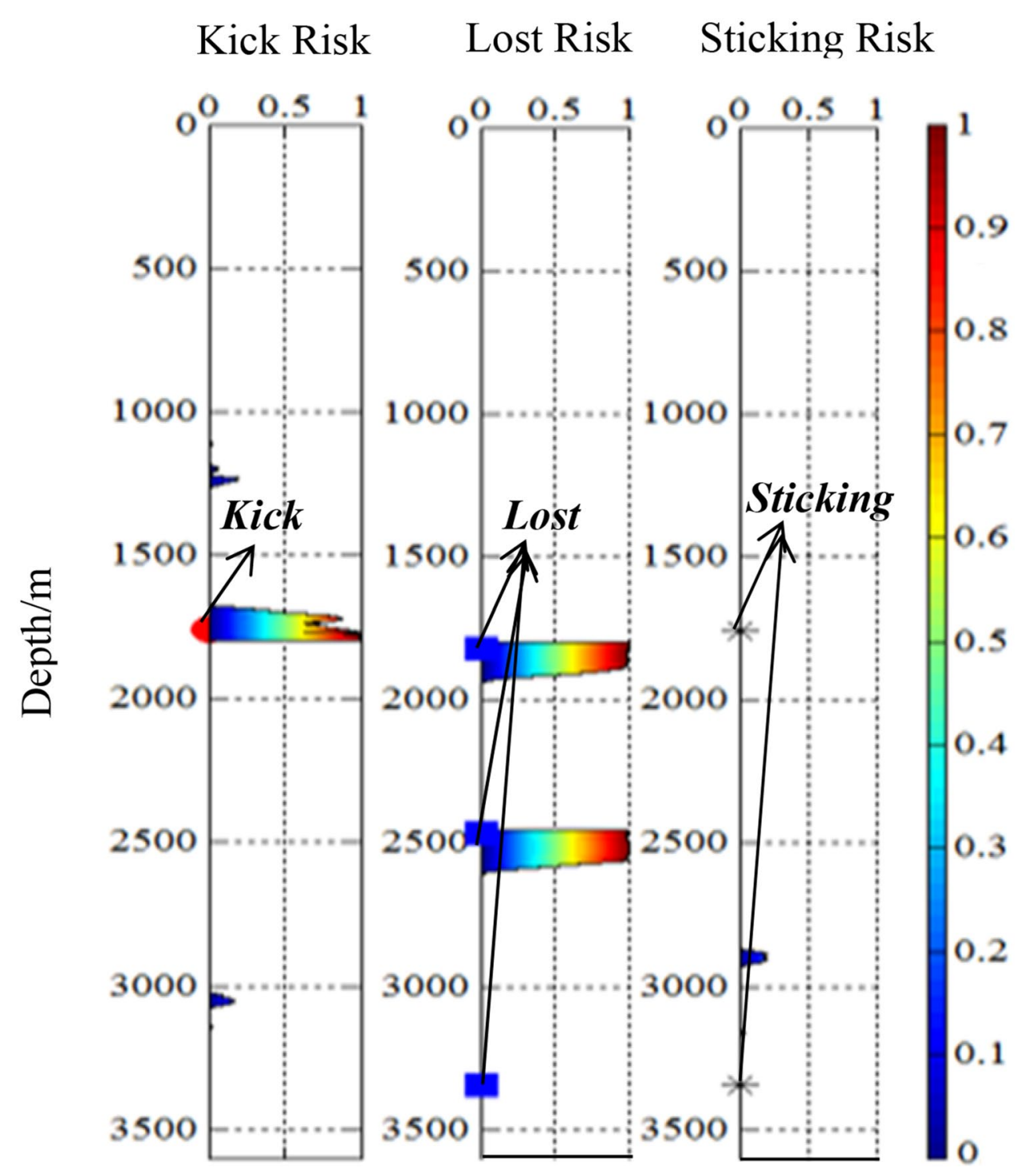


structure design method based on LWD, and the flowchart is shown in Fig. 9.

Among them, the new density window constraint of safe drilling fluid $*$ is as follows:

$\left\{\begin{array}{l}\operatorname{Pr} \text { evention of well kick: } \rho_{\mathrm{m}}\left(H_{\mathrm{i}}\right) \geq \rho_{\mathrm{p} \text { max }}^{\prime}+S_{\mathrm{b}}^{\prime}+\Delta \rho^{\prime} \\ \operatorname{Pr} \text { evention of sticking }:\left(\rho_{\mathrm{m}}\left(H_{\mathrm{i}}\right)-\rho_{\mathrm{p} \min }^{\prime}\right) \times H_{\mathrm{p} \text { min }} \times 0.00981 \leq \Delta P \\ \operatorname{Pr} \text { evention of lost circulation }: \rho_{\mathrm{m}}\left(H_{\mathrm{i}}\right)+S_{\mathrm{g}}^{\prime} \leq \rho_{\mathrm{f} \text { min }}^{\prime}\end{array}\right.$

In formula,

$\rho_{\mathrm{p} \text { max }}^{\prime}, \rho_{\mathrm{p} \text { min }}^{\prime}, \rho_{\mathrm{f} \text { min }}^{\prime}, S_{b}^{\prime}, S_{\mathrm{g}}^{\prime}, \Delta_{\rho}^{\prime}$, Variable that changes with the drilling process. $\rho_{\mathrm{p} \text { max }}^{\prime}, \rho_{\mathrm{p} \text { min }}^{\prime}, \rho_{\mathrm{f} \text { min }}^{\prime}$-The maximum formation pore pressure gradient, the minimum formation pore pressure gradient and the minimum formation fracture pressure gradient in the prediction section of the undrilled formation after the correction of LWD, $\mathrm{g} / \mathrm{cm}^{3} . S_{b}^{\prime}, S_{\mathrm{g}}^{\prime}, \Delta_{\rho}^{\prime}$-The swab pressure coefficient, surge pressure coefficient and Additional drilling fluid density, $\mathrm{g} / \mathrm{cm}^{3}$.

\section{Conclusions and suggestions}

1. In this paper, a method of formation pressure prediction with confidence based on LWD data is established. This method can modify the pressure distribution zone with confidence based on LWD data in real time, and improve the pressure prediction accuracy of the undrilled formation.

2. Based on the prediction method of formation pressure with credibility based on LWD data, combined with the restriction condition of safe density window and probability theory, a risk assessment method of dynamic well bore structure in the process of drilling is established, which can assess the risk of well bore structure in the undrilled formation in real time and quantitatively in the process of drilling.

3. This paper puts forward the design method of dynamic wellbore structure in the process of drilling, which can design the real-time dynamic wellbore structure in the undrilled formation in the process of drilling, so as to avoid the engineering risk to the greatest extent in the design level.

Acknowledgment The authors would like to acknowledge the academic and technical support of Drilling Engineering and Technology Research Institute, Zhongyuan Petroleum Engineering Co., Ltd., SINOPEC. This paper is supported by Post-doctoral project of Sinopec Zhongyuan Petroleum Engineering Company "Research on risk assessment and early warning technology of South Sichuan shale gas drilling project." Contract No.: 2020116B.

Funding Open access funding provided by Sinopec Zhongyuan Petroleum Engineering Company.
Open Access This article is licensed under a Creative Commons Attribution 4.0 International License, which permits use, sharing, adaptation, distribution and reproduction in any medium or format, as long as you give appropriate credit to the original author(s) and the source, provide a link to the Creative Commons licence, and indicate if changes were made. The images or other third party material in this article are included in the article's Creative Commons licence, unless indicated otherwise in a credit line to the material. If material is not included in the article's Creative Commons licence and your intended use is not permitted by statutory regulation or exceeds the permitted use, you will need to obtain permission directly from the copyright holder. To view a copy of this licence, visit http://creativecommons.org/licenses/by/4.0/.

\section{References}

Deli G (2004) Deep and ultra-deep well drilling technology under complex geological conditions [M]. Petroleum Industry Press, Beijing

Gundersen OE, Aamodt A (2012) A real-time decision support system for high cost well drilling operations[J]. Ai Magazine 34(1):21-32

Jianhua L, Chao W, Lisiang W et al (2013) Grey evaluation method of well loss risk and its application in Yuanba gas field [J]. Drill Fluid Completion Fluid 30(5):32-36

Ke Ke, Zhichuan G, Xing Z (2009) Determination method of formation pore pressure with reliability before drilling deep water exploration wells [J]. J China Univ Petrol(Nat Sci Ed) 33(05):61-67

Khakzad N, Khan F, Amyotte P (2013) Quantitative risk analysis of offshore drilling operations: A Bayesian approach[J]. Saf Sci 57(3): 108-117

Moos D, Peska P (2003) Comprehensive wellbore stability analysis utilizing quantitative risk assessment $[\mathrm{J}]$. J Petrol Sci Eng 38(3):97-109

Mingyan L (2007) Condition monitoring and fault diagnosis of drilling process based on neural network multi parameter fusion [J]. J China Univ Petrol (Nat Sci Ed) 31(4):149-152

Qining F (1983) Formula and method of calculating formation fracture pressure with logging data [J]. J China Univ Petrol (Nat Sci Ed) 11(3):41-48

Sayers CM, Boer LD, Nagy ZR et al (2006) Well-constrained seismic estimation of pore-pressure with uncertainty[J]. Seg Techn Progr Expand Abstr 25(1):1530-1542

Skogdalen JE (2012) Quantitative risk analysis of oil and gas drilling, using deepwater horizon as case study [J]. Reliab Eng Sys Saf 30(5):58-66

Tahmasebi P, Kamrava S (2019) A Pore-Scale Mathematical Modeling of Fluid-Particle Interactions: Thermo-Hydro-Mechanical Coupling [J]. Int J Greenhouse Gas Control 83:245-255

Xiwen J (2006) Drilling accidents and complex problems [M], 2nd edn. Petroleum Industry Press, Beijing, pp 72-80

Xiaoming Z, Pejman T (2018) Micromechanical evaluation of rock and fluid interactions [J]. Int J Greenhouse Gas Control 76:266-277

Yan J (2001) Study on theory and application of wellbore stability prediction [D]. China University of Petroleum, Beijing

Yijin Z, Jian L (2005) Development trend of deep well drilling technology [J]. Petrol Drill Technol 33(5):1-5

Zhilong L, Yingcao Z, Ruichen S et al (2009) Discussion on nonaccident risk drilling (NDS) technology [J]. Petrol Drill Prod Technol 31(1):90-94

Yingcao Z, Xiongwen Y, Shiliang F et al (2011) Development and field test of PCDS-I system [J]. Petrol Drill Technol 39(4):7-12

Zhichuan G, Yanan S, Yuqiang X et al (2017) Drilling dynamic risk assessment method based on PSO Optimized BP neural network [J]. China Work Saf sci Technol 13(8):5-11

Publisher's Note Springer Nature remains neutral with regard to jurisdictional claims in published maps and institutional affiliations. 